\title{
MicroRNA: Biogenetic and Functional Mechanisms and Involvements in Cell Differentiation and Cancer
}

\author{
Soken Tsuchiya ${ }^{1}$, Yasushi Okuno ${ }^{1}$, and Gozoh Tsujimoto ${ }^{1, *}$ \\ ${ }^{I}$ Department of Genomic Drug Discovery Science, Graduate School of Pharmaceutical Sciences, Kyoto University, \\ 46-29 Yoshida Shimoadachi-cho, Sakyo-ku, Kyoto 606-8501, Japan
}

Received June 2, 2006

\begin{abstract}
MicroRNAs (miRNAs) are endogenous small noncoding RNAs (20 - 23 nucleotides) that negatively regulate the gene expressions at the posttranscriptional level by base pairing to the 3' untranslated region of target messenger RNAs. Hundreds of miRNAs have been identified in humans and evolutionarily conserved from plants to animals. It is revealed that miRNAs regulate various physiological and pathological pathways such as cell differentiation, cell proliferation, and tumoriogenesis. By the computational analysis, it is predicted that $30 \%$ of protein-encoding genes are regulated by miRNAs. In this review, we discuss recent remarkable advances in the miRNA biogenetic and functional mechanisms and the involvements of miRNAs in cell differentiation, especially in hematopoietic lineages, and cancer. These evidences offer the possibility that miRNAs would be potentially useful for drug discovery.
\end{abstract}

Keywords: microRNA, RNA cleavage, translational repression, target mRNA, base pairing

\section{Introduction}

MicroRNAs (miRNAs) are endogenous short noncoding RNA molecules $(20-23$ nucleotides $)$ that regulate cell differentiation, cell proliferation, and apoptosis through post-transcriptional suppression of gene expression by binding to the complementary sequence in the 3' untranslated region (3'UTR) of target messenger RNAs (mRNAs) (1). Hundreds of miRNAs have been identified in humans and they are evolutionarily conserved $(1,2)$. In addition, the presence of up to 1000 miRNAs is estimated by computational analysis (3). Strikingly, $30 \%$ of protein-encoding genes in humans are predicted to be regulated by miRNAs (4). Recently, it has been revealed that altered expression of specific miRNA genes contributes to the initiation and progression of diseases such as cancer $(5-10)$. This review focuses on the biogenetic and functional mechanisms and the involvements in cell differentiation and cancer in mammalian miRNAs and the utility of

*Corresponding author. gtsuji@pharm.kyoto-u.ac.jp Published online in J-STAGE doi: 10.1254/jphs.CPJ06013X

Invited article
miRNAs in drug discovery.

\section{Mechanisms of biogenesis and function}

Most miRNA genes are located in the introns of host genes or outside genes. Unlike Drosophila, most of the human miRNA genes individually exist, although some human miRNAs are found in polycistronic clusters $(5,8,9)$.

The miRNAs are synthesized through multiple steps (Fig. 1). Initially, the miRNAs are transcribed as long RNA precursors (pri-miRNAs) (11). As pri-miRNAs usually contain the cap structure and the poly(A) tail, it is suggested that the transcription of miRNAs is carried out by RNA polymerase II (12). The primiRNAs are processed into the precursors of approximately 70 nucleotides (pre-miRNAs) with a stem-loop structure and a two nucleotide $3^{\prime}$ overhang by the RNase III enzyme Drosha and the double-strandedRNA-binding protein DGCR8/Pasha $(13,14)$, and premiRNAs are exported from the nucleus to the cytoplasm by Exportin-5 in a Ran guanosine triphosphatedependent manner (15). Pre-miRNAs exported in the cytoplasm are processed by another RNase III enzyme, Dicer, and only one strand (guide strand) as a mature 


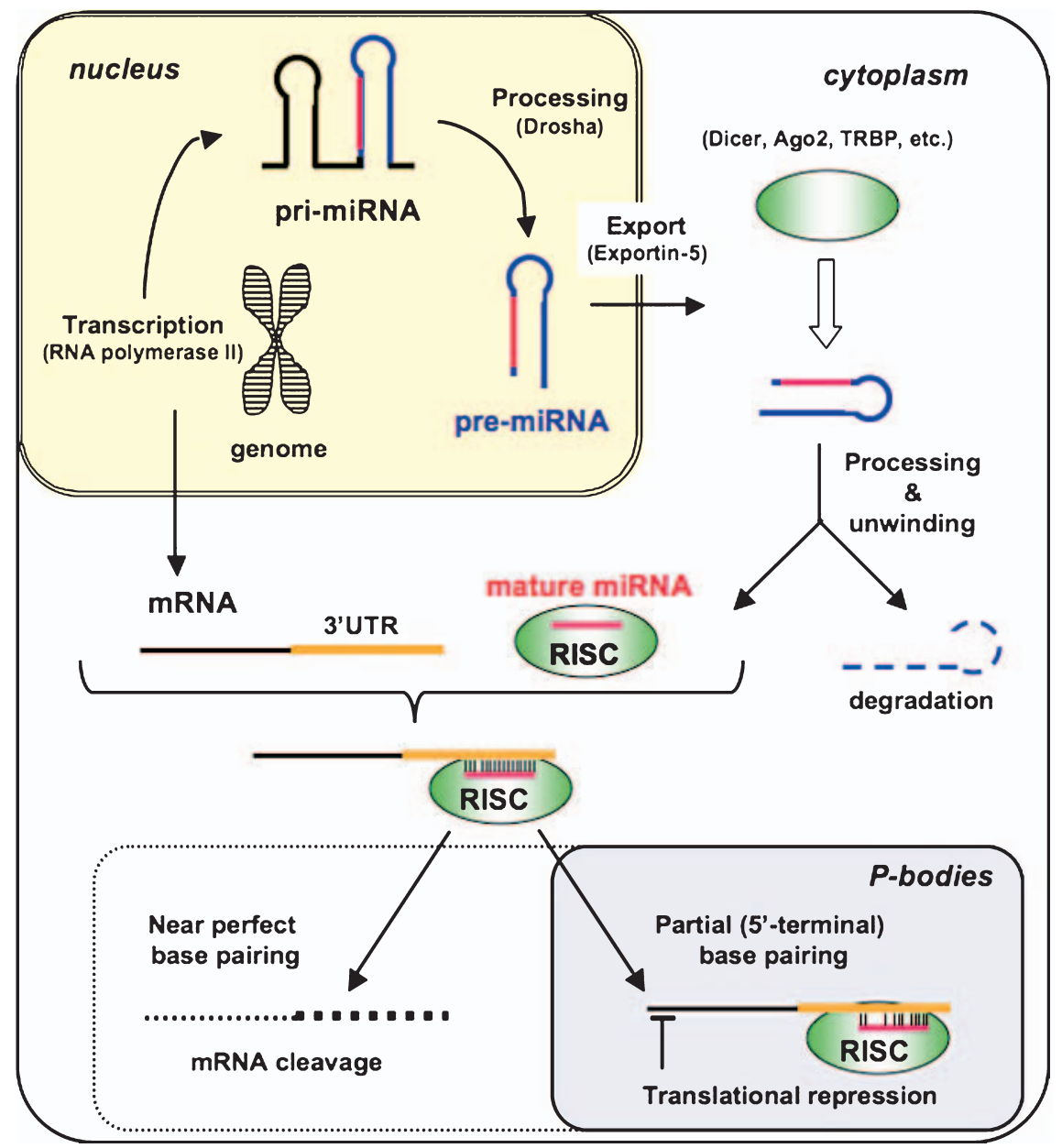

Fig. 1. Diagram of the miRNA biogenetic and functional mechanisms. Whether the target mRNA cleavage by RISC occurs in the cytoplasm or P-bodies remains unknown.

miRNA is incorporated into a RNA-induced silencing complex (RISC) that mediates either target RNA cleavage or translational inhibition, while the another strand (passenger strand) is excluded. Which strand is incorporated in RISC is determined by the stability of the base pairs at the $5^{\prime}$ end of the duplex $(16,17)$. The incorporated guide strand guides the RISC to the complementary sequence in the 3'UTR of target mRNA. When the guide strand shares perfect or near perfect base pairing with the 3'UTR of target mRNA, the target mRNA is degraded by Argonaute2 (Ago2), a component of RISC (18). On the contrary, when the guide strand shares partial base pairing, translation is target-specifically repressed without the target mRNA degradation (19). Recent studies have revealed that RISC is at least composed of Dicer, Ago2, and the double-strand RNA binding protein TRBP, and RISC efficiently processes pre-miRNAs to mature miRNAs (20). Furthermore, RISC more efficiently cleaves target mRNAs by using the pre-miRNAs than the duplex miRNAs that do not have the stem-loop. These results suggest that miRNA processing by Dicer, assembly of the mature miRNA into RISC, and target RNA cleavage by Ago 2 are coupled. Compared to the RNA cleavage mechanism by Ago2, the translational repression mechanism by miRNAs had been poorly understood. Recently, it was revealed that the target mRNAs binding to RISC through partial base pairing are accumulated in the cytoplasmic foci referred to as processing bodies (P-bodies) $(21,22)$. P-bodies, in which the mRNAs are stored or degraded by the decapping enzymes and exonucleases, do not contain the translational machinery (23). Furthermore, the disruption of P-bodies by the silencing of GW182, a key protein in P-body, inhibits translational silencing in not only partial base pairing but also perfect base pairing (24), although the localization of target mRNA with perfect base pairing is not detected in P-bodies (21). These results suggest that, at least in part, translational repression appears to be caused by the recruitment of target mRNAs to P-bodies. However, whether localiza- 
tion of the RISC-target mRNA complex in P-bodies is a cause or a result of the translational repression and whether the target mRNA cleavage by RISC occurs in the cytoplasm or P-bodies remain controversial issues.

\section{Cell differentiation}

Increasing evidence indicates that miRNAs have distinct expression patterns among tissues and cells in different differentiation stage (25). It is reported that overexpression of miR-124, which is preferentially expressed in brain, shifted the gene expression profile of HeLa cells towards that of the brain. Similarly, overexpression of miR-1 shifted the expression profile towards that of the muscle in that miR-1 is preferentially expressed (25). These results indicate that miRNAs play important roles in cell differentiation and characterization.

Recently, it was revealed that miRNAs also played critical roles in the differentiation of mammalian hematopoietic lineage. For example, miR-181 is preferentially expressed in the thymus and B-lymphoid cells of mouse bone marrow and promotes B cell differentiation by overexpression in hemapoietic stem/progenitor cells (26). Conversely, overexpression of the miR-181a, one member of the miR-181 family, was reported to repress megakaryoblast differentiation in humans (27). By the induction of megakaryoblast differentiation, the expression of endogenous miR-181a is downregulated through the acetylcholinesterase, protein kinase (PK) C, and PKA cascade. The expression of miR-130a is also downregulated by the induction of megakaryoblast differentiation (28). miR-130a targets the transcriptional factor MAFB that is a transcriptional activator of GPIIB, an important protein for platelet physiology. Furthermore, miR-223 is upregulated by the retinoic acid-induced replacement of NFI-A with CCAAT/Enhancer binding protein (C/EBP) $\alpha$, and promotes human granulopoiesis (29). As miR-223 repressed NFI-A translation, the upregulation of miR-223 by $\mathrm{C} / \mathrm{EBP} \alpha$ and granulopoiesis further accelerated through positive feedback by miR-223.

\section{Cancer}

It has been revealed that the change of miRNA expressions contributes to the initiation and progression of cancer. More than $50 \%$ of miRNAs are located in cancer-associated genomic regions or in fragile sites (5). The expression of miR-15a and miR-16, which locate as a cistronic cluster at $13 \mathrm{q} 14$, is deleted or decreased in most cases (approx. 68\%) of B cell chronic lymphocytic leukemia (B-CLL) (6). Both these miRNAs negatively regulate the expression of B cell lymphoma 2 $(\mathrm{Bcl} 2)$, that is reported to be expressed in many types of cancer including leukemias, and inhibit cell death (7). Overexpression of miR-15 and miR-16 in the MEG-01 cell line actually induces the apoptosis. Inversely, one cluster of miRNAs, miR-17-92 polycistron, was found to increase in the cancers such as B-CLL (8). The expression of six miRNAs in this cluster is upregulated by c-myc, whose expression and/or function are one of the most common abnormalities in human cancers, and miR-17-5p and miR-20a included in this cluster negatively regulate the expression of transcriptional factor E2F1 (9). Furthermore, mice reconstituted with hemotopoietic stem cells overexpressing miR-17-19b exhibit accelerated c-myc-induced lymphomagenesis (8). Furthermore, it was revealed that miRNA expression profiles enable researchers to successfully classify poorly characterized human tumors that can not be accurately classified by mRNA expression profiles (10). These results show the possibility that miRNAs have clinical benefits as not only therapeutic targets but also a tool for cancer diagnosis.

\section{Drug discovery}

miRNAs are expected to be potential targets of therapeutic strategies applied to drug discovery for a number of reasons. Firstly, in addition to the initiation and progression of tumor, miRNAs play critical roles in various biological pathways such as differentiation of adipocyte and insulin secretion and diseases such as diabetes and hepatitis. Therefore, the possibility that various human diseases are caused by abnormalities in miRNAs is indicated. Actually, miR-15 and miR-16 have been deleted or decreased in most cases of B-CLL and are identified as tumor suppressor genes $(6,7)$. Secondly, miRNA expression profiles are correlated with clinical severity of cancer malignancy, and because of this, miRNAs are expected to be powerful tools for cancer diagnosis (10). Thirdly, miRNAs are applicable in gene therapy. The expression of miRNAs can be introduced in vivo by using viral vectors and chemical modifications. Finally, antisense oligonucleotides are potent inhibitors of miRNA, and they can be applied to gene therapy. Actually, it was reported that introduction of 2'-O-methoxyethyl phosphorothioate antisense oligonucleotide of miR-122, which is abundant in the liver and regulates cholesterol and fatty-acid metabolism, decreases plasma cholesterol levels and improves liver steatosis in mice with diet-induced obesity (30). These findings indicate that miRNAs and the antisense oligonucleotides are potential targets for drug discovery. 


\section{Perspective}

It has been established that miRNAs play critical roles in cell differentiation, proliferation, and apoptosis, and the abnormalities of specific miRNA expression contribute to the initiation and progression of tumor. However, identification of target mRNAs negatively regulated by miRNAs remain largely to be explored. Although up to hundreds of target genes toward a single miRNA were predicted by bioinformatics approaches (4), there is no comprehensive assay to biologically validate the prediction algorithm. Therefore, establishment of a method to comprehensively and rapidly identify target mRNAs for the miRNA is necessary for understanding biological and functional mechanisms of miRNA.

\section{References}

1 Bartel DP. MicroRNAs: genomics, biogenesis, mechanism, and function. Cell. 2004;116:281-297.

2 Pasquinelli AE, Reinhart BJ, Slack F, Martindale MQ, Kuroda MI, Maller B, et al. Conservation of the sequence and temporal expression of let-7 heterochronic regulatory RNA. Nature. 2000;408:86-89.

3 Berezikov E, Guryev V, van de Belt J, Wienholds E, Plasterk RH, Cuppen E. Phylogenetic shadowing and computational identification of human microRNA genes. Cell. 2005;120:2124.

4 Lewis BP, Burge CB, Bartel DP. Conserved seed pairing, often flanked by adenosines, indicates that thousands of human genes are microRNA targets. Cell. 2005;120:15-20.

5 Calin GA, Sevignani C, Dumitru CD, Hyslop T, Noch E, Yendamuri S, et al. Human microRNA genes are frequently located at fragile sites and genomic regions involved in cancers. Proc Natl Acad Sci U S A. 2004;101:2999-3004.

6 Calin GA, Dumitru CD, Shimizu M, Bichi R, Zupo S, Noch E, et al. Frequent deletions and down-regulation of micro-RNA genes miR15 and miR16 at 13q14 in chronic lymphocytic leukemia. Proc Natl Acad Sci U S A. 2002;99:15524-15529.

7 Cimmino A, Calin GA, Fabbri M, Iorio MV, Ferracin M, Shimizu M, et al. miR-15 and miR-16 induce apoptosis by targeting BCL2. Proc Natl Acad Sci U S A. 2005;102:1394413949. Erratum in: Proc Natl Acad Sci U S A. 2006;103:24642565.

8 He L, Thomson JM, Hemann MT, Hernando-Monge E, Mu D, Goodson S, et al. A microRNA polycistron as a potential human oncogene. Nature. 2005;435:828-833.

9 O'Donnell KA, Wentzel EA, Zeller KI, Dang CV, Mendell JT. c-Myc-regulated microRNAs modulate E2F1 expression. Nature. 2005;435:839-843.

10 Lu J, Getz G, Miska EA, Alvarez-Saavedra E, Lamb J, Peck D, et al. MicroRNA expression profiles classify human cancers. Nature. 2005;435:834-838.

11 Lee Y, Jeon K, Lee JT, Kim S, Kim VN. MicroRNA maturation: stepwise processing and subcellular localization. EMBO J. 2002;21:4663-4670.
12 Lee Y, Kim M, Han J, Yeom KH, Lee S, Baek SH, et al. MicroRNA genes are transcribed by RNA polymerase II. EMBO J. 2004;23:4051-4060.

13 Lee Y, Ahn C, Han J, Choi H, Kim J, Yim J, et al. The nuclear RNase III Drosha initiates microRNA processing. Nature. 2003;425:415-419.

14 Gregory RI, Yan KP, Amuthan G, Chendrimada T, Doratotaj B, Cooch N, et al. The Microprocessor complex mediates the genesis of microRNAs. Nature. 2004;432:235-240.

15 Yi R, Qin Y, Macara IG, Cullen BR. Exportin-5 mediates the nuclear export of pre-microRNAs and short hairpin RNAs. Genes Dev. 2003;17:3011-3016.

16 Khvorova A, Reynolds A, Jayasena SD. Functional siRNAs and miRNAs exhibit strand bias. Cell. 2003;115:209-216. Erratum in: Cell. 2003;115:505.

17 Schwarz DS, Hutvágner G, Du T, Xu Z, Aronin N, Zamore PD. Asymmetry in the assembly of the RNAi enzyme complex. Cell. 2003;115:199-208.

18 Meister G, Landthaler M, Patkaniowska A, Dorsett Y, Teng G, Tuschl T. Human Argonaute2 mediates RNA cleavage targeted by miRNAs and siRNAs. Mol Cell. 2004;15:185-197.

19 Hutvágner G, Zamore PD. A microRNA in a multiple-turnover RNAi enzyme complex. Science. 2002;297:2056-2060.

20 Gregory RI, Chendrimada TP, Cooch N, Shiekhattar R. Human RISC couples microRNA biogenesis and posttranscriptional gene silencing. Cell. 2005;123:631-640.

21 Pillai RS, Bhattacharyya SN, Artus CG, Zoller T, Cougot N, Basyuk E, et al. Inhibition of translational initiation by Let-7 MicroRNA in human cells. Science. 2005;309:1573-1576.

22 Liu J, Valencia-Sanchez MA, Hannon GJ, Parker R. MicroRNAdependent localization of targeted mRNAs to mammalian Pbodies. Nat Cell Biol. 2005;7:719-723.

23 Andrei MA, Ingelfinger D, Heintzmann R, Achsel T, RiveraPomar R, Lu hrmann R. A role for eIF4E and eIF4E-transporter in targeting mRNPs to mammalian processing bodies. RNA. 2005;11:717-727.

24 Liu J, Rivas FV, Wohlschlegel J, Yates JR 3rd, Parker R, Hannon GJ. A role for the P-body component GW182 in microRNA function. Nat Cell Biol. 2005;7:1261-1266.

25 Lim LP, Lau NC, Garrett-Engele P, Grimson A, Schelter JM, Castle J, et al. Microarray analysis shows that some microRNAs downregulate large numbers of target mRNAs. Nature. 2005; 433:769-773.

26 Chen CZ, Li L, Lodish HF, Bartel DP. MicroRNAs modulate hematopoietic lineage differentiation. Science. 2004;303:83-86.

27 Guimaraes-Sternberg C, Meerson A, Shaked I, Soreq H. MicroRNA modulation of megakaryoblast fate involves cholinergic signaling. Leuk Res. 2006;30:583-595.

28 Garzon R, Pichiorri F, Palumbo T, Iuliano R, Cimmino A, Aqeilan R, et al. MicroRNA fingerprints during human megakaryocytopoiesis. Proc Natl Acad Sci U S A. 2006;103: 5078-5083.

29 Fazi F, Rosa A, Fatica A, Gelmetti V, De Marchis ML, Nervi C, et al. A minicircuitry comprised of microRNA-223 and transcription factors NFI-A and C/EBPalpha regulates human granulopoiesis. Cell. 2005;123:819-831.

30 Esau C, Davis S, Murray SF, Yu XX, Pandey SK, Pear M, et al. miR-122 regulation of lipid metabolism revealed by in vivo antisense targeting. Cell Metab. 2006;3:87-98. 